Swarthmore College

Works

7-1-2008

\title{
Just For The Hell Of It: A Comparison Of Two Taboo-Term Constructions
}

\section{J. Hoeksema}

Donna Jo Napoli

Swarthmore College,dnapoli1@swarthmore.edu

Follow this and additional works at: https://works.swarthmore.edu/fac-linguistics

Part of the Linguistics Commons

Let us know how access to these works benefits you

\section{Recommended Citation}

J. Hoeksema and Donna Jo Napoli. (2008). "Just For The Hell Of It: A Comparison Of Two Taboo-Term Constructions". Journal Of Linguistics. Volume 44, Issue 2. 347-378.

https://works.swarthmore.edu/fac-linguistics/19

This work is brought to you for free by Swarthmore College Libraries' Works. It has been accepted for inclusion in Linguistics Faculty Works by an authorized administrator of Works. For more information, please contact myworks@swarthmore.edu. 


\title{
Just for the hell of it: A comparison of two taboo-term constructions ${ }^{1}$
}

\author{
JACK HOEKSEMA \\ University of Groningen \\ DONNA JO NAPOLI \\ Swarthmore College
}

(Received I6 April 2007; revised I5 September 2007)

The two English constructions exemplified in Let's get the hell out of here (type G) and They beat the hell out of him (type B) differ both syntactically and semantically, but in both the taboo expression has the force of an intensifier. History (through a corpus investigation) reveals that the $\mathrm{B}$-construction started as a literal exorcism (beat the devil out of someone), where the hell substituted for the devil, and semantic bleaching ultimately made the literal sense give way to simple emphasis, with any taboo term jumping in. The G-construction may have developed simultaneously, always as an intensifier - or, perhaps, later, on analogy with B. Our analysis suggests that the use of taboo terms as intensifiers spread from $w h$-constructions to these constructions and, finally, to degree intensifier constructions. These two uses of taboo terms as intensifiers are best characterized in terms of constructions and thus offer evidence against theories lacking any notion of constructions as basic building blocks. Further, they give us information about language change: a pragmatically unified but semantically disparate class of expressions (namely, taboo terms) can extend its distribution in parallel.

Private Carr: God fuck old Bennett. He's a whitearsed bugger. I don't give a shit for him.

(James Joyce, Ulysses)

\section{INTRODUCTION}

Strong language originating from taboo expressions is interesting for a variety of reasons. It flavors our speech, it shows great variation among social groups and especially social settings, and it changes all the time. In the past, lexicographers, sociolinguists, folklorists, anthropologists and historical linguists have occasionally shown an interest in the topic (cf. e.g. Pott

[I] We thank Swarthmore College for awarding Jack Hoeksema the Cornell Visiting Professorship in 2005-2006, which allowed us to begin this work. We also thank the anonymous $J L$ reviewers and Orin Gensler for help through to the final draft. 
I833, de Jager 1858, de Baere 1940, Cameron 1969, Andersson \& Trudgill I990, Allan \& Burridge 199I, Dundes 2002 and much of the contents of the journal Maledicta), but only relatively recently have theoretically inclined linguists begun to pay attention to this matter (e.g. Brame 1978; Pesetsky I987; Postma 1995, 200I; Horn 200I; Hoeksema 200I, 2002; den Dikken \& Giannakidou 2002; Merchant 2002, 2006; Huang \& Ochi 2004; Sprouse 2005). We think it is only fitting that they should do so, for the data are not just colorful, but also instructive on a number of points.

The main goal of this paper is to analyze and compare the two English constructions exemplified in (I) and (2), respectively:

(I) (a) Let's get the hell out of here.

(b) Get the hell off my property.

(c) Shut the hell up.

(d) Leave her the hell alone.

(e) Why don't you go the hell away.

(2) I \{beat/kicked/annoyed/punched/surprised/irritated $\}$ the hell out of him.

We show that these constructions, despite their surface string similarity, differ syntactically and semantically, and that their analysis is best characterized in terms of constructions as building blocks. An interesting byproduct of this study is the light shed on historical change in general: taboo terms are shown to extend their distribution to varying syntactic structures in a parallel way. This suggests that a pragmatically unified but semantically disparate class of expressions can be treated as a unit by the grammar.

\section{A REMARK ON THE CORPUS}

Certainly a study of the syntax of the two constructions at issue could be carried out strictly by tapping into native speakers' intuitions, which we have done to a large extent. However, in order to delve into the history of these constructions, we needed access to a written corpus.

We therefore base our discussion in part on a corpus investigation, largely using material from scanned books and newspapers available through the Google website. In addition, we used online newspaper material from LexisNexis, as well as e-texts from the Gutenberg project, and material from various websites accessed through Google.

Reasons for using this material, rather than existing diachronic corpora, include the need for size (many books do not contain a single instance of the constructions we are interested in, so we needed a big corpus), and the possibility, offered by Google Books and the archive part of Google News, to search for books and newspapers from a particular period (say, material published between 1850 and I900). We have used this material with caution, fully aware of the many scanning errors it contains, deciding not to use 
material when we doubted its true publication date. From these various sources, we collected a total of Iooo occurrences, judging that to be sufficient to paint a reasonably accurate picture of the distributional and historical trends that we are interested in.

\section{TABoo TERMS AND THEIR LINGUISTIC EXPLOITATION}

Taboo terms come from a number of sources and are used in a wide variety of domains. We will briefly list the main sources for English, and then discuss the various ways in which the taboo terms are used. The purpose of this section is to show that the class of taboo terms is semantically diverse, but pragmatically coherent.

There are three major sources of taboo terms in English. Many terms, especially older ones, stem from religious and folk beliefs, such as those having to do with the devil, hell, God, Jesus Christ, saints, heaven, salvation and damnation. Sexual acts and reproductive organs also provide strong linguistic taboos, even today, in spite of the sexual revolution of the r96os and I970s. Finally, bodily excretions constitute powerful taboo topics, and provide us with an additional set of taboo terms to choose from (and see Horn 2004 for an exposition of the bodily fluid imagery behind the expression spitting image).

Other possible taboo topics, such as money, though compared to feces by Freud (I913), do not seem to have been used in strong language of the type considered here, nor do the group of life, death, and diseases except in namecalling (You scrofulous idiot!, and see Potts \& Roeper 2006), although other languages make wider use of this group (Van Sterkenburg 200I, Kehayov 2006). Race is also a taboo topic in polite conversation, but it, like money, is not a source for strong language in English, apart from epithets used to put racial and ethnic groups down. Extreme political or social positions can be taboo among certain people as well, and can give rise to epithets, such as the general bigot or the more specific feminist - it all depends on the speaker's point of view. We also can call people animals in some of the same kinds of situations in which we employ taboo terms, but few of these terms have the force of a taboo (an exception being bitch).

Taboo terms are used in many ways. We will discuss only some, because a more complete discussion would take us too far far afield. The best-known use of taboo terms is probably in exclamations, i.e., cursing and swearing, as in (3a) and the quasi-curses that stand for the real McCoy in ( $3 b)$ :

(3) (a) Damn!/Fuck!/Shit!

(b) Darn!/Fudge!/Shoot!

Name-calling is another frequent use:

(4) You $\{$ devil/cumdumpster/turd $\}$ ! 
Closely related to swearing and name-calling are maledictions, often taking the form of imperatives:

(5) Go to hell!/Suck a hairy moose cock!/Eat shit and die!

Taboo terms can be used as predicates with non-literal meanings:

(6) That sucks!/She shits on us all the time!

Often particle verbs of taboo origin form rude expressions for telling people to go away:

(7) $\{$ Fuck/Piss $\}$ off!

They can be used as pejorative modifiers:

(8) the professor from hell/a dick thing to do/a shitty proposal

Some taboo terms develop into degree adverbs:

(9) (a) He's hell-bent on doing it./You're so damned clever.

(b) He's butt ugly./That's fucking awesome.

(c) She's spitting mad./He's rabidly insane.

Notice that fucking in (9b) functions as an intensifier, in contrast to its use elsewhere as a pejorative modifier (What a fucking dickwad). We note in passing that cases like hell bent or butt ugly are elative compounds, but they can nonetheless be viewed as involving intensification by modification in exactly the same way as more clearly phrasal cases of adverb + adjective. Still others are used in similar ways in resultative and comparison constructions to indicate a high degree:

(Io) He was funny as hell./We were scared shitless.

Taboo terms can express emphatic rejection or denial, as well as emphatic assertion. The denial or negative contradiction construction contains no overt standard negation element, but uses a preposed taboo term instead:

(II) $\{$ The/Like $\}$ hell/fuck $\}$ I will.

Emphatic assertions with taboo terms, however, are not restricted to a single construction type:

(I2) (a) You bet your $\{$ (sweet) ass/booty $\}$ I am.

(b) Damn \{right/straight $\}$.

(c) Sure shit.

(d) Does the bear shit in the woods?

(e) I'm not shitting you.

It is also possible to put a taboo term in front of yes, no and yeah:

(I3) Hell yes!/Fuck no!/Shit yeah! 
Both denials and assertions of these types are appropriate only as a response to another statement, and may not be syntactically embedded:

(I4) (a) A: I hear you're going to marry a Norwegian woman.

B: (*I believe that) The hell I will.

(b) A: I hear you're going to marry an Italian woman.

B: (*I believe that) You bet your sweet ass I am.

English $w h$-questions (including rhetorical ones) may be made more emphatic by means of various taboo terms (as well as some free relative clauses: I will do whatever the hell you do, although not all free relatives permit the intrusion of expletive elements: *I will do what the hell you do; Fillmore I985: 8I):

(I5) (a) $\{$ Who/Where/What $\}$ the $\{$ hell/fuck $\}$ are you?

(b) Why the hell should I care?/What the shit is going on?

Important to note for our later discussion is that some taboo terms are used as negative polarity items (cf. Horn 200I, Postma 200I, Hoeksema 2002, Postal 2005). Subsets can be distinguished, such as minimizers with a pejorative adjectival modifier of taboo origin:

(I6) I can't see a $\{$ damned/fucking/bloody $\}$ thing.

as well as mass nouns (sometimes with an added particle all):

(17) They didn't \{say dick/know jack shit about it.

Terms in the latter, but not the former, set may also appear without any form of overt negation, while still carrying a negative sense (Horn 200I, Postal 2005), which means they have undergone a turn of the Jespersen cycle (Jespersen 1917):

(I8) They did $\{$ dick/shit $\}$ about it, that's what they did.

A third set of negative polarity expressions are of the form give an $X$, where $\mathrm{X}$ is typically, though not exclusively, some taboo term:

(i9) give a $\{$ damn/hoot in hell/(flying) fuck/rat's ass/crap/shit\}

Most of these can appear without the negative while still carrying the negative sense, parallel to the examples in (I8).

The above examples of various constructions employing taboo terms are meant not only to illustrate the use of taboo terms, but also to make a more serious linguistic point. The constructions vary widely, and have very little in common, apart from the fact that they all appear to have an emotionally charged character. In these constructions, the taboo terms behave like syntactic silly putty that can be bent and shaped every which way. Normally, the enlistment of lexical items by a construction is based on the category and features of the items in question, and these in turn are in part determined by 
lexical semantics, and in part arbitrary. In taboo constructions, however, lexical meaning appears to play no role. If anything, these constructions show the victory of connotation over denotation. The fact that taboo terms have a certain rude quality about them is more relevant than their meaning. This is quite obvious when we consider the many constructions where fuck may be used instead of hell. Semantically, the two words are rather different, apart from their taboo status. We address the theoretical import of such spreading in section 6 .

\section{TWO CONSTRUCTIONS}

The two English taboo-term constructions analyzed in this paper have identical surface strings: verb + taboo term + PP (although the final part, the coda, can vary). The first we call GET-THE-HELL-OUT, or the G-construction, as seen in (I) above and in (20):

(20) Let's get the hell out of this cow town./Back the hell off!

The second we call BEAT-THE-HELL-UP, or the B-construction, as seen in (2) above and in (2I):

(2I) They're beating the hell out of Jones./She scares the hell out of me.

Evidence that they are syntactically distinct follows.

\section{I Object status of the taboo term}

The taboo terms in the B-construction are direct objects, whereas their counterparts in the G-construction are not. For one thing, taboo terms cannot be omitted from the B-construction, whereas they can from the G-construction:

(22) (a) They scared *(the shit) out of me.

(b) They got (the hell) out of the car.

Additional evidence comes from the possibility of passivization. While ordinary passives are at best marginal in the B-construction (cf. (23d)), get and have passives (cf. $(23 \mathrm{~b}-\mathrm{c}))$ are fine:

(23) (a) They kicked the shit out of Jones.

(b) Jones got the shit kicked out of him (by them).

(c) Jones had the shit kicked out of him (by them).

(d) ?The shit was kicked out of Jones (by them).

Compare with the poor results of trying to do the same with the G-construction:

(24) (a) They stayed the hell away from John.

(b) *John got the hell stayed away from him. 
(c) *John had the hell stayed away from him.

(d) *The hell was stayed away from John.

(Cf. They stayed the execution again vs. The execution was stayed again.)

Correlating in a loose way is the transitivity status of the verbs in the Band G-constructions. In our collection of Iooo natural occurrences of constructions $B$ and $G$, we found the distribution of transitive and intransitive verbs as presented in table I. (The numbers in the table don't add up to Iooo because of I 5 cases not involving verbs, which we omit here. We discuss these cases in section 4.7 below.)

\section{CONSTRUCTION INTRANSITIVE TRANSITIVE}

\begin{tabular}{crr} 
G & 455 & 48 \\
$\mathrm{~B}$ & 4 & 478 \\
\hline \multicolumn{3}{c}{ Table I } \\
\multicolumn{3}{c}{ Transitivity and construction type }
\end{tabular}

The correlation is striking, and definitely significant, but not absolute. ${ }^{2}$ This is due, in part, to the fact that G-construction sentences like $(25 \mathrm{a}, \mathrm{c})$ may have transitive counterparts such as $(25 \mathrm{~b}, \mathrm{~d})$ :

(25) (a) Let's get the hell out of the car.

(b) Let's get him the hell out of the car.

(c) Let's run the hell out of town.

(d) Let's run 'em the hell out of town.

In these transitive cases, it is even clearer that the taboo term the hell is not a direct object, since the object position is occupied here by the pronouns him and 'em respectively. Again, passivization makes the point:

(26) Those cattle rustlers \{were/got\} run the hell out of town.

(Since passivization of main-verb get yields poor results, independent of the taboo constructions, we do not provide a passive counterpart to (25b).)

Another factor involved in making the correlation in table I less than perfect is the existence of intransitive verbs partaking in the B-construction. The four examples in our collection are $:^{3}$

[2] Using Fisher's Exact Test, two-tailed, we found that $\mathrm{p}<0.000 \mathrm{I}$.

[3] Another example, involving the verb gripe, which is intransitive in the authors' usage, may involve a rare occurrence of the transitive meaning 'annoy, bug', which some dictionaries, e.g. Webster's (McKechnie I983), distinguish as slang:

(i) That gripes the hell out of you, doesn't it?

(Laurents I949: 64)

The Oxford English Dictionary (OED) gives several examples of transitive gripe, the last one from 1943 . 
(27) (a) She can walk the shit out of a lengthy platform ...

(b) You make me laugh the shit out of myself ...

(c) I used LimeWire Pro to download porn and masturbate the hell out of my dick ...

(d) I sat in the waiting area, shaking my foot, fixing my shoelaces, basically fidgeting the hell out of myself.

Again, these putative exceptions corroborate our proposal when looked at more closely. Intransitive verbs in general can occur with cognate objects, as in (28).

(28) She slept the sleep of the weary.

Here slept and sleep are morphologically related. But such objects need not be actually morphologically related to the verb; so long as the object represents the referential extension of the action of the verb, it is acceptable:

(29) She cried crocodile tears./It rained cats and dogs.

In these instances, the direct object serves to add information to the manner of the action of the verb. That is, we don't learn that the action was done to a particular thematic argument; rather, we learn that the action proceeded in a particular way. Generally the manner information we get concerns the degree of the activity. In sleeping the sleep of the weary, we know that the sleep was long and heavy. In crying crocodile tears, we know that this was a noisy, showy action.

Functionally similar fake DOs can be licensed by a resultative:

(30) (a) I am going to walk these shoes *(to pieces).

(b) We will laugh ourselves *(silly).

Resultatives do not always have a literal interpretation; instead, some may be used as degree expressions. For instance, starving to death may literally be dying caused by starvation; but being bored to death does not usually mean one is dying as a result of boredom, but, rather, denotes a high degree of boredom. It is with this type of interpretation in mind that we see the examples in (27) as having fake objects, akin to those in both cognate-object constructions and resultatives. Walking the shit out of a lengthy platform (as a model might) means walking that platform very well or very often, and beating the hell out of someone is not to cause the hell to come out of someone by means of rather forceful exorcism, but to beat someone a lot, to a high degree of intensity.

If we think of the relation between beat Harry and beat the shit out of Harry as a verb alternation (à la Levin 1993), it is clear that it has the following properties: the regular DO of beat is turned into the object of a preposition (out of ) and the place of the DO is now taken up by a definite NP involving some taboo $\mathrm{N}$ : the hell, the shit, etc. The object of the preposition is 
still interpreted as the theme or patient of whatever action is described by the verb, while the entire construction indicates a high degree of intensity for the action in question.

\subsection{Polarity issues}

Den Dikken \& Giannakidou (2002) argue that what the hell and other reinforced $w h$-items are polarity items of a particular sort. When embedded under a predicate such as know, which is not specifically a question predicate, they are best when know in turn appears in a nonveridical environment. A nonveridical environment for some proposition $\mathrm{p}$ is one that does not permit one to infer the truth of $\mathrm{p}$ (Zwarts 1995, Giannakidou 1998). Examples of nonveridical environments are complements of intensional verbs, the scope of negation, conditionals, questions, modal contexts, imperatives, etc. Compare:

(3I) (a) ?I know where the hell he lives. ${ }^{4}$

(b) I don't know where the hell he lives.

(c) I want to know where the hell he lives.

(d) Pray tell me where the hell he lives.

(e) Do you know where the hell he lives?

(f) Only his parents know where the hell he lives.

The G-construction, on the other hand, is a positive-polarity construction $:^{5}$

(32) (a) *Don't get the hell off my property!

(b) *Jones did not get the hell out of Dodge.

(c) *Let's not get the hell out of here.

Note that the examples in (32) are more acceptable with contrastive or echoic negation, something which is generally true of positive polarity items (see

[4] According to den Dikken \& Giannakidou (2002), this sentence should receive an asterisk. We believe it is only mildly disfavored, but not starkly ungrammatical. In fact, veridical occurrences of know are attested on the Internet, but relatively rare (we estimate them to be about $10 \%$ of occurrences of know + wh the hell).

[5] As noted in van der Wouden (1997), positive polarity items are not all alike. Some only shun the presence of direct negation while others prefer to avoid from a larger set of negative environments. Some negative contexts appear fairly generally to permit positive polarity items, for instance conditional clauses. Compare (i), where the relevant positive polarity item is something:

(i) If you say something/anything critical of the state, you may get arrested.

Therefore an example such as (ii) below, offered by one of the referees, is not a problem for our claim that the G-construction acts as a positive polarity item:

(ii) If you get the hell off my property, I won't call the police. 
Seuren I985, Horn I989, among others). This may be hard to show in the case of (32a), which is an imperative, but (32b) could be used in a context such as:

(33) Jones was told to get the hell out of Dodge, but Jones never does as he is told. So he did not get the hell out of Dodge.

The same is true for constituent negation. In (34) not negates the adjunct for nothing, but leaves the main assertion intact (i.e. Jones got out of Dodge).

(34) Jones did not get the hell out of Dodge for nothing.

Also, it is well-known that when negation is embedded in questions, conditionals, or other negative contexts, yielding a double negation context, the occurrence of positive polarity items is often grammatical (Baker I970, Horn I989, Szabolcsi 2004); compare:

(35) (a) I'll beat you if you don't get the hell off my property!

(b) Why don't you get the hell off my property!

(c) You can't say he did not get the hell out of here.

It may appear odd that the hell sometimes produces negative polarity items and sometimes positive polarity items, but it is actually not uncommon for lexically similar expressions to diverge in this way (Hoeksema I996).

The B-construction, unlike the G-construction, is not a positive polarity item, and may appear with ordinary negation, without any need for special echoic intonation or double negation contexts:

(36) (a) We did not beat the hell out of him.

(b) AIDS does not scare the shit out of people anymore.

(c) I don't straighten the hell out of my hair anymore; curly is in.

(d) Nothing could depress the hell out me; I'm an optimistic sort

\subsection{Choice of verbs}

The two constructions are clearly distinguished by the verbs they enlist. As is apparent from table 2 , the most common verbs in the B-construction involve some kind of physical abuse verb, such as beat, kick, knock, shoot, smash, sock, etc. In addition, a large group of psychological verbs also can be used in this construction, some of which, such as scare and frighten, appear quite frequently. Mostly, verbs in the B-construction have a negative connotation, but more positive ones also show up, such as impress.

In the special case of beat, we note that the expletive may equally combine with this verb when it is used literally, or when it is used as part of the idiom that beats (the hell out of ) me ('I don't have a clue'). On the other hand, the idiom beat it ('go away', as in the eponymous Michael Jackson hit song) does not seem to occur in the B-construction. We assume that the verb alternation involved requires the object of the complex preposition out of to be able to bear a thematic role. This will prevent verbs with dummy objects 


\begin{tabular}{|c|c|c|c|c|c|c|c|c|c|}
\hline VERB & $\mathrm{N}$ & VERB & $\mathrm{N}$ & VERB & $\mathrm{N}$ & VERB & $\mathrm{N}$ & VERB & $\mathrm{N}$ \\
\hline admire & I & creep & I & kick & 34 & razz & I & sue & I \\
\hline advertize & I & crush & I & knock & 36 & recruite & $I$ & surprise & I \\
\hline amuse & I & curse & I & laugh & I & repress & I & taunt & I \\
\hline annoy & IO & cut & 2 & lick & 5 & resent & I & $\operatorname{tax}$ & I \\
\hline $\begin{array}{l}\text { bad- } \\
\text { mouth }\end{array}$ & I & dash & I & like & 2 & respect & I & tear & 2 \\
\hline bash & 7 & dent & I & love & 5 & ride & I & tease & I \\
\hline batter & I & depress & I & market & I & rip & 3 & terrify & 2 \\
\hline beat & 98 & distract & I & mash & I & rout & I & thank & I \\
\hline belt & I & eat & I & masturbate & I & sand & I & throw & 2 \\
\hline bend & I & edit & I & miss & I & scare & 94 & tickle & 2 \\
\hline bite & I & e-mail & I & $\begin{array}{l}\text { misunder- } \\
\text { stand }\end{array}$ & I & scratch & I & train & I \\
\hline blast & 3 & embarrass & I & $\operatorname{mix}$ & I & screw & I & trash & I \\
\hline blow & 5 & enjoy & 3 & mother & I & shake & 3 & walk & I \\
\hline bomb & 4 & excuse & I & nuke & I & shell & I & wallop & 3 \\
\hline bore & 3 & fidget & I & pamper & I & shock & I & wear & I \\
\hline bother & 2 & frighten & 8 & pester & I & shoot & 8 & welt & I \\
\hline bug & 2 & frustrate & I & pistol-whip & I & sing & I & whack & 3 \\
\hline bum & I & gripe & I & pound & 3 & slap & 3 & whale & I \\
\hline burn & I & hammer & I & practice & I & slash & I & whip & I \\
\hline challenge & $I$ & hype & I & promote & 3 & smash & 5 & worry & I \\
\hline confuse & 2 & impress & IO & pummel & I & sock & I & & \\
\hline cook & I & intimidate & I & punch & 3 & splash & 2 & TOTAL & 482 \\
\hline corrode & I & investigate & $I$ & push & I & spoil & I & & \\
\hline $\begin{array}{l}\text { counter- } \\
\text { punch }\end{array}$ & I & irritate & 5 & race & I & squeeze & I & & \\
\hline cover & I & jam & I & rape & I & stomp & I & & \\
\hline crayon & I & jar & I & rattle & I & suck & 2 & & \\
\hline
\end{tabular}

Table 2

Verbs in the B-construction

from undergoing the alternation. Compare also I'm gonna cut the hell out of this dress with Good grades alone won't cut (*the hell out of) it anymore in the competitive world of college admissions.

The large number of verbs occurring just once in our data points to a considerable productivity of the B-construction. ${ }^{6}$ One need only google the

[6] See Baayen (199I) for an insightful discussion of the value of unique occurrences of words (so-called hapax legomena) in the estimation of the productivity of morphological processes on the basis of corpus data. The measure used by Baayen can also be applied to estimate the 


\begin{tabular}{lrlrlr}
\hline VERB & N & VERB & N & VERB & N \\
\hline back & I & hurry & 5 & slow & I \\
be & 8 & keep & 6 & smack & I \\
bring & I & leave & 26 & stay & 25 \\
calm & 3 & let & I & steer & 4 \\
chase & I & lick & I & sure & I \\
chill & I & lighten & 2 & take & I \\
drink & I & live & I & think & I \\
drive & I & lock & I & throw & I \\
drop & 5 & look & I & wait & I \\
fade & I & puke & I & want & I \\
fly & 2 & pull & I & & \\
freak & I & run & 6 & TOTAL & 498 \\
get & 3 I5 & shut & 49 & & \\
go & I3 & sit & 3 & & \\
\hline
\end{tabular}

Table 3

Verbs in the G-construction

fixed string the hell out of to find many more verbs in this construction on the Internet. It is not our aim to provide complete lexicographical coverage of the construction, but rather to give a representative sample of the kinds of verbs involved, as well as which ones are most commonly used.

The set of verbs used in the G-construction (table 3) shows almost no overlap with the set of verbs listed in table 2 .

It may come as a surprise that the G-construction, though slightly more common than the B-construction, is actually less productive, in that it shows less variety in the choice of verbs. In interpreting table 3 , the reader should bear in mind that some of the verbs are part of a verb-particle combination, where we lump particles with intransitive prepositions (Emonds 1976: 174). So shut, for instance, is found frequently because of the particle verb shut up, as in Shut the hell up! Similarly, leave is a frequent verb in the list because of leave alone, cf. Leave me the hell alone! Since the most common meaning component of the predicates in the G-construction is movement, it may seem odd to list shut up or leave alone under the rubric of the G-construction. Clearly, this decision needs to be motivated, and we will do so in the next

productivity of syntactic patterns such as the B-construction studied here. Given that the B-construction has 87 unique verbs in our data set, and the G-construction 24, Baayen's measure would rate the B-construction as about 3 to 4 times as productive as the G-construction. Other measures, such as type/token ratios, show a similar difference in productivity and lexical diversity. 
section. In the mean time, we note that none of the verbs listed in table 2, when occurring in the B-construction, are part of particle verbs. ${ }^{7}$

\subsection{Choice of taboo terms}

In table 4 we show the frequencies of the various taboo terms that we have found in our data set, dividing them over the two constructions $\mathrm{G}$ and $\mathrm{B}$. Fifteen special cases that did not clearly belong to either G or B were left out of the table. See section 4.7 for discussion.

We see in table 4 that the B-construction not only shows greater productivity when it comes to verbs, but also with regard to taboo terms. In fact, the majority of taboo terms found in the B-construction do not appear in the G-construction, nor are they legitimate there, according to our intuitions. While some of the items listed (e.g. the living pudding) are clearly one-off cases, usually found on the Internet and showing creative rather than conventionalized use of language, most are robustly attested.

Compare, for instance, (37) and (38):

(37) (a) Let's get the $\{$ hell/*shit/*bejesus $\}$ out of Dodge.

(b) Shut the $\{$ fuck $/$ hell $/ *$ shit $/ *$ bejesus $\}$ up.

(c) Leave her the $\{$ fuck/hell/heck/*shit/*bejesus $\}$ alone.

(38) (a) They beat the $\{$ hell/fuck/shit/bejesus $\}$ out of him.

(b) The police kicked the $\{$ hell/fuck/shit/bejesus $\}$ out of them.

(c) That scares the $\{$ hell/fuck/ shit/bejesus $\}$ out of me.

The asterisks in (37)-(38) reflect the native-speaker judgments of student and faculty informants at Swarthmore College in the early months of 2006. Not all speakers have such a clear distinction, as one of our reviewers pointed out to us. However, it would appear that the Swarthmore academic community we tested is, in fact, revealing a tendency that others share. On 24 June 2007, we googled 'shut the X up' (with the quotation marks) and 'beat the X out of' (again, with quotation marks), where for $\mathrm{X}$ we substituted (hell/fuck/shit/ bejesus\}. Table 5 shows the number of hits for each taboo term in the two constructions and the percentage of the total number of occurrences of each construction we googled.

Certainly, the bejesus, being somewhat archaic, should not be expected to occur often. But it did occur in I. $3 \%$ of the tokens of the B-construction phrase we tested (beat the X out of ), whereas it occurred in only $0.000024 \%$ of the tokens of the G-construction phrase (shut the $X u p$ ). So, at least with respect to these two phrases, it is highly disfavored in the G-construction, to

[7] The cases with be are special in that they all involve constructions with specifiers after $b e$ : (i) And Bruckman and his boys are way the hell over in Canada. 


\begin{tabular}{|c|c|c|c|}
\hline ITEM & G & B & TOTAL \\
\hline a living hell & & I & I \\
\hline hell & & 28 & 28 \\
\hline Satan & & I & I \\
\hline spots & & I & I \\
\hline he Beelzebub & & I & I \\
\hline the bejeebies & & 3 & 3 \\
\hline the bejesus & & I6 & I6 \\
\hline the bloody bejeebies & & I & I \\
\hline the bloody fuck & I & 3 & 4 \\
\hline the bloody hell & I & & I \\
\hline the breath & & 2 & 2 \\
\hline the crap & & $2 \mathrm{I}$ & $2 \mathrm{I}$ \\
\hline the creeps & & I & I \\
\hline the daylights & & 3 & 3 \\
\hline the deuce & 2 & 3 & 5 \\
\hline the devil & & 7 & 7 \\
\hline the dickens & & I & I \\
\hline the everlasting shit & & I & I \\
\hline the ever-living shit & & I & I \\
\hline the everloving fuck & I & & I \\
\hline the everloving shit & & I & I \\
\hline the fickety fuck & I & & I \\
\hline the flying fuck & I & & I \\
\hline the fuck & I74 & I3 & I87 \\
\hline the fucking fuck & I & & I \\
\hline the heck & 26 & 50 & 76 \\
\hline the hell & 290 & I2I & $4 \mathrm{II}$ \\
\hline the holy hell & I & I & 2 \\
\hline the holy shit & & I & I \\
\hline the life & & 20 & 20 \\
\hline the literal hell & & 3 & 3 \\
\hline the living bejesus & & 3 & 3 \\
\hline the living crap & & 9 & 9 \\
\hline the living daylights & & 36 & 36 \\
\hline the living doo squat & & I & I \\
\hline the living dooky & & I & I \\
\hline the living fuck & I & I & 2 \\
\hline the living fudge & & I & I \\
\hline the living hell & & 7 & 7 \\
\hline
\end{tabular}

Table 4

(Continued) 


\begin{tabular}{|c|c|c|c|}
\hline ITEM & G & B & TOTAL \\
\hline the living piss & & 3 & 3 \\
\hline the living pudding & & I & I \\
\hline the living shit & & 5 & 5 \\
\hline the living smurf & & I & I \\
\hline the living snot & & I & I \\
\hline the living tar & & I & I \\
\hline the motherfucking fuck & I & & I \\
\hline the piss & & 3 & 3 \\
\hline the proverbial fuck & I & & I \\
\hline the shit & & $7 \mathrm{I}$ & $7 \mathrm{I}$ \\
\hline the snot & & 4 & 4 \\
\hline the spit & & 2 & 2 \\
\hline the stuffing & & 8 & 8 \\
\hline the tar & & I5 & I5 \\
\hline the tarnation & I & 3 & 4 \\
\hline TOTAL & 503 & 482 & 985 \\
\hline
\end{tabular}

Table 4

Taboo terms in the G- and B-constructions

\begin{tabular}{lrrrr}
\hline ITEM & G & $\%$ & B & $\%$ \\
\hline the hell & $6 \mathrm{I} 2,000$ & 29.4 & 255,000 & 36.7 \\
the fuck & $\mathrm{I}, 450,000$ & 69.6 & 22,300 & 3.2 \\
the shit & $2 \mathrm{I}, 200$ & $\mathrm{I} .0$ & 408,000 & 58.8 \\
the bejesus & 5 & & 8,920 & $\mathrm{I} .3$ \\
TOTAL & $2,083,205$ & & 694,220 & \\
\hline
\end{tabular}

Table 5

Occurrences on 24 June 2007 of hell, fuck, shit, and bejesus in shut the $X$ up and beat the $X$ out of

the point where we could say that the five people who used it are exhibiting an idiosyncracy. We must conclude that all other taboo terms tested are grammatical in both constructions for these phrases. However, the shit is clearly much less common in the G-construction, accounting for only $\mathrm{I} \%$ of the hits, and the fuck is much more common for the G-construction, accounting for a whopping $69.6 \%$ of the hits. Still, the $\{$ hell/fuck $\}$ occur with high frequency in both constructions. 


\begin{tabular}{lrrrrr}
\hline ITEM & G & $\%$ & B & $\%$ & TOTAL \\
\hline the fuck & I 74 & 93 & I3 & 7 & I 87 \\
the hell & 290 & 7 I & I2I & 29 & $4 \mathrm{II}$ \\
the heck & 26 & 34 & 50 & 66 & 76 \\
TOTAL & 490 & 73 & I 84 & 27 & 674 \\
\hline
\end{tabular}

Table 6

Restricted to fuck, hell, and heck

With this in mind, it is instructive to return now to our original corpus and compare the two constructions with respect to the $\{$ hell/fuck\}, adding in the taboo term the heck, since it occurred frequently in both constructions. Table 6 restricts the data from table 4 to just these items. We see that the fuck shows a strong preference for $\mathrm{G}$ over $\mathrm{B}$, that the hell has a weaker preference in the same direction and that heck favors the B-construction. Given the intuitive ranking $f u c k>$ hell $>$ heck on a scale of strength or rudeness, this suggests that the G-construction is ruder than the B-construction. We believe that this is indeed the case, and that it has to do with another difference between the two constructions, to be dealt with in the next subsection.

Based on table 6, the choice of expletives in the G-construction provides us now with a criterion to establish whether shut the hell up or leave her the fuck alone should be regarded as instances of the G-construction, in spite of the fact that they do not involve motion. We simply note that the particle verbs shut up, leave alone and others readily combine with the three expletives that show up in the G-construction, but not nearly so readily with the other ones. We already compared the frequent shut the $\{h e l l / f u c k\}$ up with the very infrequent (I\%) shut the shit up and the almost nonexistent shut the bejesus up in table 5. A quick google search on 24 June 2007 of 'leave her the $X$ alone' (with quotation marks), substituting hell, fuck, shit, crap, and bejesus for X resulted in a total of 5I69 hits, of which 46Io were for fuck $(89.2 \%), 554$ for hell (I.I\%), 3 for crap, 2 for shit, and none for bejesus.

\subsection{Directiveness}

Many occurrences of the G-construction are directive. Most common among these are commands, such as Get the hell off my property!, but adhortative sentences also frequently occur, such as Let's get the hell out of here! and We should get the hell out of this place. A third type of clause, which we have treated as an embedded directive, is the complement of a predicate such as order or tell: The sarge told us to get the hell out. On the other hand, sentences such as So we got the hell out or They beat the hell out of him are nondirective, regular descriptions. We marked up all our data for directiveness, and found 


\begin{tabular}{lcrc}
\hline & \multicolumn{2}{c}{ CONSTRUCTION } & \\
\cline { 2 - 3 } DIRECTIVE? & $\mathrm{G}$ & $\mathrm{B}$ & TOTAL \\
\hline No & $\mathrm{I} 23$ & 470 & 593 \\
Yes & 380 & $\mathrm{I} 2$ & 392 \\
TOTAL & 503 & 482 & 985 \\
\hline
\end{tabular}

Table 7

Directiveness for two constructions

a very strong correlation between the G-construction and directiveness, shown in table $7 .{ }^{8}$ While only a handful of the occurrences of the B-construction were directive, $75 \%$ of the occurrence of the G-construction were.

It seems natural to assume that it is more at variance with common rules of politeness to tell someone to get the hell out than it is to report that someone got the hell out. Hence the ruder terms are best saved for directives, whereas the more socially acceptable ones, such as heck, will be relatively more common in nondirective utterances. Of course, we do not claim that commands involving the G-construction are always rude or that they must convey something negative to the hearer, but rather that they frequently are, and do.

With the B-construction, the force of the expletive is simply emphasis. When an editor tells an author 'We're going to sell the hell out of this book', nothing nasty is implied. Quite generally, the expletive is not related to the attitude of the speaker toward the listener. With the G-construction, however, the attitude of the speaker to the listener does appear to be relevant, at least with directives. Directive utterances (with or without expletives) often convey bluntness, rudeness, or anger. These connotations are so strong that textbooks for second language learners of English include warnings against them in their sections on pragmatic competence (Bland 1996 offers a thorough discussion). Of course, both the situation of the speech act and the intonation of the speaker can counter this effect, in which case the expletive is simply an indication of urgency and/or speed: Jones got the hell out of the burning barn.

Indirect (embedded) directives, usually with speech act predicates such as tell, order, give orders, etc., derive their properties from direct speech acts. So they too express some kind of emotional connotation, ascribable, in this case, not to the speaker of the entire utterance, but to the agent of the speech act verb, who is held responsible for the content of the embedded clause.

[8] Using Fisher's Exact Test, two-tailed, we found that $\mathrm{p}<0.000 \mathrm{I}$. 


\begin{tabular}{lrcr}
\hline TYPE OF CODA & G & B & TOTAL \\
\hline PP & 265 & 482 & 747 \\
P & 95 & & 95 \\
Adv & 73 & & 73 \\
A & 65 & & 65 \\
Other & 5 & & 5 \\
TOTAL & 503 & 482 & 985 \\
\hline
\end{tabular}

Table 8

Codas for two constructions

\subsection{Choice of coda}

The syntactic category of the coda, i.e. the expression following the expletive, may also serve to distinguish the G- and B-constructions.

\subsection{The various types of codas}

Table 8 lists the type of codas in our data for the two constructions at hand. While both constructions show mostly PPs in coda position, the G-construction also has codas of the category P (prepositional particle), Adverb or Adjective. ${ }^{9}$ This is enough, of course, to show that $\mathrm{G}$ and $\mathrm{B}$ differ in this regard as well. The differences are, moreover, not merely statistical in nature, but categorical, as predicted by our account. We have argued that the B-construction involves a verb alternation which turns a direct object into a PP complement headed by out of. Hence it is to be expected that only PP codas are to be found. Even the closely related particle codas do not show up in the B-construction, because they cannot host the verb's theme argument.

We find the status of codas interesting enough to warrant additional discussion in the following subsections.

\subsubsection{The coda is a PP}

It is clear from table 8 that PPs are by far the most common type of coda. Yet it is equally obvious that not all PPs make good codas for our two expletive constructions. Here we address the criteria that are relevant to PP selection.

[9] The category 'other' contains some unusual formations, including the only case of a DP coda we found: $u$ were born white stay the fuck that way cunt! Here, the adverbial nature of the expression that way might tempt one to treat it as a PP with an unpronounced $\mathrm{P}$ (cf. e.g. McCawley 1988, against Larson 1985). Other exceptional cases were the combinations get going and get cracking, as in the following example: If you don't know the Apostle's Creed, then grab a book and get-the-fuck-cracking. 
First, we note that the B-construction always involves out of or its phonological variant outta. Sentences such as (39), from our corpus, are not problematic for this claim since they are not examples of the B-construction:

(39) That church attempts to scare the bejesus into people.

The bejesus here is not telling the degree to which people will be scared, but is, rather, the theme argument, while people is the locatum argument. That is, the reading of (39) is that the church uses scare tactics to make people believe in their teachings. In fact, we can substitute other theme arguments with no problem:

(40) His dad tried to scare some $\{$ sense/caution/decency\} into him.

However, a quick google search of 'scare the $X$ into' on 24 June 2007 , revealed that some people do use scare the $X$ into as a variant of scare the X out of when $\mathrm{X}$ is a taboo term. We found only one hit for scare the fuck into, but 610 hits for scare the shit into (as compared to 132,000 hits for scare the shit out of ). We also found 32 hits of scare the bejesus into, but most (if not all) of them, like our (39) above, were in religious contexts and were to be read similarly to (39).

While there is nothing more to be said about the PPs in the B-construction, there is much to say about them in the G-construction. In table 9, we give an overview of the Ps found in our data set for the G-construction.

The most common preposition is the complex $\mathrm{P}$ out of, but others are attested as well, in particular, directional prepositions indicating motion away from some pragmatically-given pivot, usually the speaker or the subject of the sentence. For prepositions that are polysemous (the majority), directional uses may be acceptable whereas nondirectional ones are not to the same degree. For example, we found (4Ia) on the Internet, but no one we asked accepts (4Ib):

(4I) (a) Run the hell about the house.

(b) *Let's talk the hell about the war.

Some fairly idiomatic cases do exist, however, such as this one from the Internet:

(42) Pay attention and get the hell with it.

In short, it is the predominance of PPs with out of that makes the G- and B-constructions look similar at first, and conversely it is the possibility of a range of Ps that sets the G-construction apart from the B-construction.

\subsubsection{The coda is a particle}

When the coda is a particle, we are dealing with the G-construction. The B-construction only accepts out of-PPs as its coda (with the minor exception 


\begin{tabular}{lrr}
\hline PREPOSITION & N & $\%$ \\
\hline around & $\mathrm{I}$ & 0.4 \\
at & 2 & 0.8 \\
away from & 8 & 3.0 \\
down & $\mathrm{I}$ & 0.4 \\
from & $\mathrm{I}$ & 0.4 \\
in & 4 & $\mathrm{I} .5$ \\
in front of & $\mathrm{I}$ & 0.4 \\
into & $\mathrm{I}$ & 3.8 \\
off & 28 & $\mathrm{I}$ \\
on & 2 & 0.6 \\
onto & 2 & 0.8 \\
out & 2 & 0.8 \\
out of & $\mathrm{I} 86$ & 70.2 \\
over & $\mathrm{I} 3$ & 4.9 \\
through & 2 & 0.8 \\
up to & $\mathrm{I}$ & 0.4 \\
with & $\mathrm{I}$ & 0.4 \\
TOTAL & 265 & \\
\hline
\end{tabular}

\section{Table 9}

Prepositions in the G-construction

we noted in section 4.6.2). Particle verbs are common in the G-construction, however, especially shut up, hurry up, get out, get off, get up. Less common were back up, chill out, drink up, drive off, freak out, go out, lock up.

\subsubsection{The coda is an adverb}

Adverbs in coda-position form a very small group of items with clear PP-like characteristics: away, back, back down, down, here, there, home, inside, outside and now. The cases with now and here in our data set are special in that they do not involve a verb (for example: Right the hell now!), and so they do not immediately strike one as candidates for either the G- or the B-construction. We defer the discussion of these cases to section 4.7 , where we will consider a number of other problems as well.

The items back, down, home, inside and outside are all adverbs that behave like directional PPs in some ways, and like particles of particle verbs in other ways. For instance, they may be conjoined with directional PPs:

(43) (a) The prospectors went back and into the cave.

(b) The police went inside and into the kitchen. 
Jackendoff (I973) mentions similarities between back, down, etc. and PPs, such as the fact that both may be the locative argument of put:

(44) (a) Sheila put the clothes in the closet/inside/on

(b) Irving put the books \{on the shelf/there/away\}

Another test he uses for PP status is modification by right:

(45) (a) The eager dwarves rushed right \{into her arms/inside/back $\}$.

(b) Just go right \{to the traffic light/back/in/home\}.

On the other hand, these adverbs may also be found in preverbal position in verbal compounds, like particles but unlike full PPs: downsizing, homecoming, inside-trading are like uplifting, outgoing, ongoing but unlike *inthebackstabbing, *at-home-cooking, etc. It is conceivable that the sheer bulk of full PPs is what makes them resistant to incorporation.

Another difference, already noted by Jackendoff, concerns the positional possibilities of particles, in contrast to PPs:

(46) Sheila put $\{\mathrm{on} / \mathrm{back} / *$ in the closet $\}$ the clothes.

While we generally agree with the asterisk in (46), we note that with enough context and appropriate prosody, the in the closet variant can be made to sound relatively natural. So we believe that here, as well as in the case of incorporation, heaviness may come into play. Light elements may appear in between the verb and the direct object, heavy items are disfavored, unless the direct object itself is heavy:

(47) Sheila put in the closet all the clothes that she had found on the floor.

The best argument for the view that heaviness is at stake comes from the well-known fact that pronouns do not normally appear after particles, unless they are given extra stress (indicated here by boldface) or made heavier by attached modifiers:

(48) Sheila called up $\{*$ him/him/only him $\}$.

Given the similarities among PPs, particles, and adverbs of the back-, down-, here-class, we may view the codas of the G-construction as PP-like entities.

\subsubsection{The coda is an adjective}

Among the remaining expressions, primarily adjectives, the most prominent by far is alone, in the combination leave alone. This adjective exhibits PP-like behavior. Alone, together with some other adjectives beginning in $a$-, such as asleep, awake, alive, afraid, ajar, tends not to occur in the usual adnominal position of attributive adjectives (Markus I998: I35):

(49) ?an $\{$ alone/afraid/alive $\}$ student 
although, as Markus notes (following Quirk, Greenbaum, Leech, \& Svartvik 1985), the results are generally better when the adjectives in question are modified:

(50) (a) a somewhat \{alone/afraid\} student

(b) a really alive student

Historically, most $a$-adjectives derive from PPs, and the positional preferences of these adjectives still reflect their origin (Markus 1998). Thus the $O E D$, s.v. $a$-, states that akin derives from of kin, with $a$ - as a reduced form of of (compare also outta<out of, e.g. we got to get outta here), and that ado stems from at do, while yet others, e.g. abed, ashore, alive derive from on: on bed, on shore, on live. While alone does not actually derive from a PP, but from the combination all-one, it was most likely reanalyzed at some point as a member of the class of $a$-adjectives. The existence of the adjective lone, without the $a$-, provides some evidence for such a reanalysis. Further evidence can be seen in the behavior of degree modifiers. Like PPs, but unlike most adjectives, $a$-adjectives do not use the degree modifier very but rather the complex modifier very much: $:^{10}$

(5I) very $(*$ much $)\{$ nice/talented

(52) (a) *very \{out of her mind/into Greek art

(b) very much \{out of her mind/into Greek art \}

(53) (a) ?very alone

(b) *very aghast

(c) very much \{alone/aghast\}

In other words, it looks like the distributional properties of $a$-initial adjectives coming historically from a PP source were grammaticalized, spreading in turn to alone on the basis of phonological similarity.

However, while we believe that the PP-like characteristics of alone may have helped the combination leave alone in becoming by far the most palatable host for the hell and its ilk, it is not in fact the only such combination that is attested. Other examples of the form verb +expletive + adjective are given here:

(54) (a) ... let me get back to work and then let me the hell alone.
(b) ... if I shoot it, it goddamned well better drop the hell dead!
(c) Get the hell better so we can all get shit faced.
(d) ... and sometimes you just want to get the hell drunk.
(e) Be sure to get the hell stuffed!

\footnotetext{
[1о] Some $a$-adjectives combine with both very and very much, such as afraid. The line Be afraid, be very afraid, from the 1986 horror film The Fly, starring Jeff Goldblum and Geena Davis, has become a winged word in recent times.
} 
The examples all appear to involve complex predicates: leave alone, let alone, drop dead, get better, get drunk, get stuffed, stay clear of, steer clear of. Adjectives occurring with the more common verbs be or become are hardly attested.

\subsection{Special cases}

We find the hell, the fuck and other taboo terms following some intensifiers:

(55) (a) So the hell off the mark.

(b) Right the hell \{now/here\}.

(c) All the hell around the world.

(d) Way the fuck over in Canada.

The intensifier licenses the taboo terms; its absence yields ungrammaticality:

(56) (a) John's in *(way) the fuck over his head.

(b) Just watch; she'll be *(all) the fuck over him at the party.

(c) She dove *(deep) the fuck under - I mean deep, baby.

The examples in (55)-(56) are neither B-constructions nor G-constructions. Rather, this use of taboo terms can appear anywhere the appropriate intensifiers can appear. In (56) they go with intensifiers of PPs. But in (57) they go with intensifiers of an AP, a VP, and an NP:

(57) (a) AP: You went so the fuck wrong, I can't begin to explain.

(b) VP: She so the fuck doesn't understand.

(c) NP: He's so the fuck a liar.

Just as we saw with wh-expressions in (I5) above, which also license taboo terms, the addition of the hell or the fuck adds force, so much force, in fact, that the fuck is more common than the hell in this usage, and degree adverbs that do not have a strong intensifier sense cannot license them:

(58) *She's $\{$ a little/a bit/somewhat $\}$ the fuck frightened.

The intensifier that most commonly licenses taboo terms is so. Indeed, the frequency of taboo terms after intensifier so may be responsible for the appearance of them after other uses of so. For example, the affirmative propredicate $s o$, which is anaphoric rather than an intensifier, can license taboo terms:

(59) (a) A. I'm tired of all this fighting.

(b) B. Oh, yeah? Well, so the fuck am I!

And the idiom so what can be broken up by inserting a taboo term:

(6o) So the hell what? 
The licensing of taboo terms by intensifiers is a relatively new phenomenon in English. Yet it should be no surprise. We already have taboo terms functioning as intensifiers with $w h$-words and in the B- and G-constructions (the history of this development is presented in section 5). It is a quick jump, then, to taboo terms combining with other intensifiers to make a kind of super-intensifier, so that so stupid becomes so the fuck stupid and too dumb to understand becomes too the fuck dumb to understand. In the judgments of our Swarthmore informants, the expletives used with intensifiers are those we find with the G-construction, in particular the hell/fuck, rather than the more mild ones that are found so often in the B-construction. Compare:

(6I) (a) so the $\{$ hell/fuck $\}$ stupid

(b) *so the $\{$ shit/crap $\}$ stupid

\section{History of the two CONSTRUCTIONS}

The B- and G-constructions first appear in printed texts toward the end of the nineteenth century and these early attestations of both constructions involve religious terms only, such as the devil and the hell. Accordingly, we conjecture that they originated around that time. It is conceivable that they arose much earlier in the spoken language, but we have no evidence that this was actually the case. It is always a difficult task to estimate when a new word or idiom enters the language on the basis of written language, and this difficulty is exaggerated when dealing with taboo terms, which one might expect to be limited to the most informal of exchanges. However, some of the taboo terms were obviously not too rude for the Victorians to use in print, given that expressions like who the devil or why the deuce show up quite regularly in Igth-century novels, as they did before and after. If the use of taboo terms in the G- and B-constructions does not show up much in Igth-century sources, we think it likely that this is not because it was considered insufferably crude, but because the constructions were too new and not yet in wide circulation. Evidence for this claim comes from one of the first attested cases of the G-construction that we have been able to find, in a Senate report:

(62) Get the hell out of here.

(Lexow \& Cantor I895: 4665)

Proceedings of US Senate Hearings often contain vivid, informal language, but certainly not anything considered unprintable. If it were deemed extremely rude, we would expect rather different sources for the earliest occurrences of the hell in the G-construction, such as personal correspondence or naturalistic novels.

An early occurrence of the B-construction is:

(63) Say, old man, you must have knocked the devil out of her coming over alone in twenty-nine days!

(Slocum 1900: 47) 
The context of this example is relevant. The pronoun her is referring to a sailing vessel, and so it is clear that the use of knock the devil out is idiomatic, and does not refer to some exorcism ritual. Earlier occurrences of the devil + out typically denote religious practices, and do not appear to be idiomatic.

\section{I The B-construction}

It is likely that one origin of the B-construction is exorcism: beating the devil out of somebody. Most early occurrences of beat the devil out of $X$ describe either actual exorcism of the devil or a beating meant to rectify a rebellious or wayward spirit. The origin of the B-construction is hard to date because of the difficulty in distinguishing the earlier exorcism interpretation from the later intensifier reading. Sometimes the choice of the verb may help here. If it is drive the devil out of $X$, or cast the devil out of $Y$, we assume that exorcism is the intended interpretation. With many modern examples, however, we can be unequivocal in our analysis of them as examples of the B-construction because no exorcism reading is possible; often they do not even involve verbs of physical or mental abuse, and many employ the taboo term the fuck, which precludes an exorcism reading.

When the verb is beat or scare, matters are a bit more complex. Our best guess is that the B-construction goes back at least to the latter half of the I9th century. The oldest occurrence of the B-construction we have been able to find in Google Books dates from I895:

(64) Yes, Loubitza will beat the devil out of her when she gets her home her and her broken jar!

(Daintrey I885: 74)

At some point, the expletive must have 'bleached' to the extent that it became solely an intensifier. The original meaning of exorcism still shines through in newer variants such as beat satan out of or the one in the following example from the Internet, where the context shows that religious and intensifier uses are being played upon:

(65) When 'Charlie's Angels' beat the Beelzebub out of Adam Sandler's 'Little Nicky', bringing the second week gross of Drew Barrymore, Cameron Diaz, and Lucy Liu's T\&A blockbuster to a heavenly $\$ 75$ million, the triumph of seraphim over Satan seemed divine. And in true Hollywood tradition, the next question wasn't 'How do I thank thee, Lord?' but rather 'How fast can we make a sequel?' For Sony, it's not going to be a piece of angel food cake.

The substitution of the hell for the devil in the B-construction may well have taken place under the influence of an earlier change in English strong language involving what the devil, etc. being replaced by what the hell. This change probably started in the late I8th or early I9th century, well before the 
earliest attestations of beat the hell out of $X$, etc. The oldest attestations we have been able to find are from the early igth century, e.g.:

(66) (a) I wonder what the hell brings us here again?

(b) Him! why what the hell is he but a priest? (Carleton I845: 244)

The substitution the devil > the hell may also help explain why hell is preceded by an article, something it normally does not have in English (cf. Go to hell, Hell is a hot place, etc.), where hell is treated, like heaven for that matter, as a proper name. We should note, however, that up to roughly the I920s, the more common variant in the B-construction is beat/punch/etc. hell out of X, without the article. Compare e.g. the following examples:

(67) (a) Sheridan [...] used some rather strong language and said that he would 'knock hell out of Stuart if he could get at him'.

(Indiana County Gazette, November 6, 1890)

(b) Tom Tarkington also testified that Goodman told him during the day that he was going to whip hell out of the appellant.

(Court of Criminal Appeals of Texas, June I2, I90I)

(c) One of them mots that do be in the packets of fags Stoer smokes that his old fellow welted hell out of him for one time he found out

(Joyce 1922: 247)

The addition of the article was probably reinforced by the earlier adoption of the hell in $w h$-questions, where the bare noun is very rare and appears to be possible only when a preposition is present:

(68) (a) What *(the) hell are you doing?

(b) What in hell are you driving at?

Even more striking is the later occurrence of the fuck, again obtained by simply substituting one noun for another, leaving intact the article. Had it not been for the prior existence of the hell and the devil, we would not have expected the fuck to be used in this way. (The same argument applies to rarer forms such as who in the hell, who in the world which led to the peculiar substitution form who in the fuck.)

Apart from religious contexts involving exorcism, there appears to be another source of the construction, not involving expletives such as the devil but, instead, the life: beat the life out of $X$, scare the life out of $Y$, strangle the life out of $Z$, etc. These involve a similar bleaching, moving from descriptions of attempts on someone's life to mere intensification:

(69) And that's what's frightening the life out of me. (Christie I940: I56)

We note that words for life and death are often used for purposes of intensification, compare e.g. These sermons bore me to death or I can't understand 
for the life of me what the hell he is talking about, and the use of dead as an adverb of degree: dead wrong, dead tired, dead certain. Again, it is difficult to pinpoint exactly when the literal use developed into the intensifier use, but it is plausible that this happened in the Igth century.

Attested from the second half of the Igth century onward is beat/scare the living daylights out of $X$, cf.:

(70) ... he started to club the living daylights out of the beast with his gun

(Decatur Morning Review, Io September 1890)

It is hard to tell whether the scatological variants beat the shit out of $X$ or scare the crap out of $Y$ are more recent than the religious ones, because of the strong taboo which the Victorian age put on words for excrement. However, the Oxford English Dictionary (2nd edition, Simpson \& Weiner 1989) has not come up with anything antedating Leonard Cohen's 1966 LP Beautiful Losers, and neither have we. It is highly likely, then, that the expression is not as old as the variants involving the devil and his residence.

The use of the fuck in the G-construction is probably from around the same time. The oldest attestations in print we were able to find are from the late i960s:

(7I) (a) Get the fuck off me!

(Rollins I967: II3)

(b) Get the fuck out of here.

(Walker I968: 225)

At the moment, we see a flowering of ever-longer variants on the Internet:

(72) (a) ... get the living fuck out of my house!

(b) And then I get the proverbial fuck out.

(c) You people are mother fuckers that deserve to get the everliving fuck beaten out of you for being worthless human beings.

(d) He squeezed off a couple of rounds in the air and we thought that would be a good time to do a three-point turn and get the raging fuck out of there.

(e) He got into his car yelling something at her and she said 'That's right you effing abuser, get the effing hell out of here'.

(f) ... get the flying fuck out of my face or I'll puke on you

Similar developments can be noted in the B-construction, as well as $w h$-intensification. For the latter, compare such examples as:

(73) (a) ... then where in the holy living fuck did all those cavemen and cannibals and headhunters and Mesolithic horticulturalists come from?

(b) How the fickety fuck-bums are you ma wee sex-communist?

(c) ... how in the blue fuck is that even possible???

(d) ... what the friggin hell is a 'bisexual'?

(e) Who the motherfucking fuck do you think you are? 


\subsection{The G-construction}

The G-construction is much easier to identify, even in its first occurrences, than the B-construction. The oldest attestation we have been able to find, so far, is (62) above, repeated below, from I895:

(62) Get the hell out of here.

It appears, then, that the B- and G-constructions are about equally old. There is no strong evidence that one gave rise to the other, but the similarities between the two constructions, and the fact that they both at some point substituted the fuck for the hell, suggest that they are closely related and developed in tandem. If one construction derived from the other, we surmise that the G-construction was derived from the B-construction. This might explain why the oldest attestations of the G-construction involve the preposition out of and why out of-PPs are still by far the most common type of coda. The precise mechanisms and manner of such a derivation, if correct, remain murky, however.

\section{SUMMARY AND OUTLOOK}

The B- and G-constructions studied in this paper seem at first glance to be a single construction, but we have shown that they differ in both syntactic and semantic structure. In the B-construction the taboo term has the grammatical role of direct object, but is not an argument of the verb, the thematic argument being the object of the complex preposition out of. Non-thematic dummy objects are precluded. In the G-construction there is neither a direct object nor a thematic argument of the verb. The B-construction employs only a PP headed by out of, while the G-construction most frequently employs out-of PPs, but also allows a variety of adjuncts, including other PPs, particle Ps, Adverbs, and Adjectives. The verbs in the B-construction are transitive and typically have to do with physical or mental abuse, while the verbs in the G-construction are mostly intransitive. There is a wide range of taboo terms in the B-construction, but the G-construction tends toward only a few and the strongest. This last fact correlates with the fact that the G-construction is frequently a directive.

In both constructions the taboo term functions as an intensifier, of the action of the verb in the B-construction and of the attitude of the speaker in the G-construction. Other positions in which taboo terms function as intensifiers include after $w h$-words, after degree intensifiers such as so, and in emphatic denial or assertive statements. Our analysis here suggests that the use of taboo terms as intensifiers spread from the wh-constructions to the B- and G-constructions and, finally, to the degree intensifier constructions. 
The occurrences of taboo terms in a great many different constructions makes sense only if we assume two things:

- some constructions have a special emphatic status in the language, and show a tendency to employ taboo terms to express that status

- once items are enlisted by some constructions, they may (but do not have to) spread to other constructions as well

The spread from one construction to another might be viewed as a type of grammaticalization. The historical developments we have discussed in the two major constructions analyzed in this paper strongly indicate that pragmatic cohesion (evidenced in the fact that these constructions have a special emphatic status) suffices to initiate such grammaticalization, which can then have a ripple effect on historical change, so that we find similar taboo terms functioning in similar ways in structures that are disparate both semantically and syntactically.

Theories of grammar that assume constructions as their basic building blocks, such as Construction Grammar (Fillmore, Kay \& O'Connor 1988, Goldberg 1995), to some extent also HPSG and TAG-grammar, predict that phenomena such as the one described in this paper might readily occur. On the other hand, theories which do not admit constructions into their repertory of syntactic primitives, such as Chomsky's Minimalist Program (Chomsky 1995) or classical versions of categorial grammar (Lambek I958), do not predict their occurrence. Rather, in such theories the appearance of these particular taboo terms in all these different constructions is mere coincidence, and leads to no predictions about the possible syntactic environments that new taboo terms might occur in. For example, if a new term were coined for a sex act, we might expect it sooner or later to appear in a subset of the syntactic positions that fuck can occupy in theories that admit constructions as syntactic primitives, but not in theories that don't. Indeed, fictive expletives do occur in the relevant syntactic slots. The failure of the latter set of theories to make this kind of prediction is problematic, given that in censored environments people will even substitute nonsense words such as 'bleep' in the relevant syntactic slots.

\section{REFERENCES}

Allan, Keith \& Kate Burridge. 199I. Euphemism and dysphemism: Language used as shield and weapon. New York: Oxford University Press.

Andersson, Lars \& Peter Trudgill. 1990. Bad language. Oxford: Blackwell.

Baayen, Harald. I99I. Quantitative aspects of morphological productivity. In Geert E. Booij \& Jaap van Marle (eds.), Yearbook of morphology I99I, I09-I49. Dordrecht: Kluwer.

Baker, C. Lee. 1970. Double negatives. Linguistic Inquiry I, I69-186.

Bland, Susan Kesner. 1996. Intermediate grammar: From form to meaning and use. New York: Oxford University Press.

Brame, Michael K. I978. Base generated syntax. Seattle, WA: Noit Amrofer.

Cameron, Paul. 1969. Frequency and kinds of words in various social settings, or what the hell's going on? The Pacific Sociological Review I2.2, IOI-I04. 


\section{J. HOEK SEMA \& D. J. NAPOLI}

Carleton, William. I845. Valentine M'Clutchy, the Irish agent. Dublin: James Duffy, London: Chapman and Hall \& Edinburgh: Oliver and Boyd.

Chomsky, Noam. 1995. The Minimalist program. Cambridge, MA: MIT Press.

Christie, Agatha. 1940. And then there were none. New York: St. Martins Press. [Reprint.]

Cohen, Leonard. 1966. Beautiful losers. Toronto: McClelland and Stewart Ltd.

Cunningham, Allan. I826. Paul Jones. Edinburgh: Oliver and Boyd.

Daintrey, Laura. I885. The king of Alberia: A romance of the Balkans. London: Methuen $\& \mathrm{Co}$.

de Baere, Cyriel. 1940. Krachtpatsers in de Nederlandsche volkstaal: Een verzameling oudere en jongere bastaardvloeken. Antwerp: N. V. de Nederlandsche Boekhandel.

de Jager, Arie. I858. De versterkte ontkenning in onze taal, vooral bij de middelnederlandse schrijvers. In Arie de Jager, Latere verscheidenheden uit het gebied der Nederlandsche taalkunde, 59-I54. Deventer: A. ter Gunne.

den Dikken, Marcel \& Anastasia Giannakidou. 2002. From hell to polarity: 'Aggressively non-D-linked' wh-phrases as polarity items. Linguistic Inquiry 33.I, 3I-62.

Dundes, Alan. 2002. Much ado about 'sweet bugger all': Getting to the bottom of a puzzle in British folk speech. Folklore II 3, 35-49.

Emonds, Joseph E. 1976. A transformational approach to English syntax. New York: Academic Press.

Fillmore, Charles J. 1985. Syntactic intrusions and the notion of grammatical construction. In Mary Niepokuj, Mary VanClay, Vassiliki Nikiforidou \& Deborah Feder (eds.), The Eleventh Annual Meeting of the Berkeley Linguistics Society, 73-86. Berkeley, CA: Berkeley Linguistics Society.

Fillmore, Charles J., Paul Kay \& Mary Catherine O’Connor. I988. Regularity and idiomaticity in grammatical constructions: The case of let alone. Language 64, 50I-538.

Freud, Sigmund. I9I3. Totem und Tabu: Einige Übereinstimmungen im Seelenleben der Wilden und der Neurotiker. Leipzig \& Vienna: Hugo Heller.

Giannakidou, Anastasia. 1998. Polarity sensitivity as (non)veridical dependency. Amsterdam: John Benjamins.

Goldberg, Adele. 1995. Constructions: A Construction Grammar approach to argument structure. Chicago: University of Chicago Press.

Hamilton, Steve. 200I. Winter of the Wolf Moon. New York: St. Martin's Press.

Hoeksema, Jack. I996. Zeg het met rozen: Een vergelijking van drie idiomatische uitdrukkingen. Tabu 26.3, I29-I49.

Hoeksema, Jack. 200I. Rapid change among expletive polarity items. In Laurel J. Brinton (ed.), Historical linguistics 1999: Selected papers from the I4th International Conference on Historical Linguistics, Vancouver, 9-I3 August 1999, I75-I86. Amsterdam: John Benjamins.

Hoeksema, Jack. 2002. Minimaliseerders in het standaard-Nederlands. Tabu 32.3/4, I05-174.

Hoeksema, Jack, Hotze Rullmann, Víctor Sánchez-Valencia \& Ton van der Wouden (eds.). 200I. Perspectives on negation and polarity items. Amsterdam: John Benjamins.

Horn, Laurence R. 1989. A natural history of negation. Chicago: University of Chicago Press.

Horn, Laurence R. 200I. Flaubert triggers, squatitive negation and other quirks of grammar. In Hoeksema et al. (eds.), I73-202.

Horn, Laurence R. 2004. Spitten image: Etymythology and fluid dynamics. American Speech 79.I, $33-58$.

Huang, C.-T. James \& Masao Ochi. 2004. Syntax of the hell: Two types of dependencies. In Kier Moulton \& Matthew Wolf (eds.), North Eastern Linguistic Society (NELS) 34, 279-293. Amherst, MA: Graduate Linguistics Student Association, University of Massachusetts.

Jackendoff, Ray S. 1973. The base rules for prepositional phrases. In Stephen R. Anderson \& Paul Kiparsky (eds.), A Festschrift for Morris Halle, 345-356. New York: Holt, Rinehart and Winston.

Jespersen, Otto. I9I7. Negation in English and other languages. Copenhagen: Videnskabenes Selskab.

Joyce, James. 1922. Ulysses. Oxford: Oxford University Press. [Reprint I998.]

Kehayov, Petar. 2006. Taboo-intensifiers as polarity items: Evidence from Estonian. Ms., University of Tartu. 
Lambek, Joachim. 1958. The mathematics of sentence structure. American Mathematical Monthly 65, I54-170.

Larson, Richard K. 1985. Bare-NP adverbs. Linguistic Inquiry I4, 595-62I.

Laurents, Arthur. 1949. Home of the brave. New York: Dramatists Play Service, Inc.

Lee, Harry. 1948. Sir and brother. New York: Appleton-Century-Crofts.

Levin, Beth. 1993. English verb classes and alternations: A preliminary investigation. Chicago: University of Chicago Press.

Lexow, Clarence \& Jacob A. Cantor. I895. Report and proceedings of the Senate Committee Appointed to Investigate the Police Department of the City of New York. Albany, NY: J. B. Lyon.

Markus, Manfred. 1998. A-adjectives (asleep, etc.) in postnominal position: Etymology as a cause of word order (corpus-based). In Antoinette Renouf (ed.), Explorations in corpus linguistics, I35-I46. Amsterdam \& Atlanta, GA: Rodopi.

McCawley, James D. 1988. Adverbial NPs: Bare or clad in see-through garb? Language 64.3, 583-590.

McKechnie, Jean L. (ed.). 1983. Webster's deluxe unabridged dictionary, 2nd edn. Cleveland, $\mathrm{OH}$ : Dorset and Baber.

Merchant, Jason. 2002. Swiping in Germanic. In Jan-Wouter Zwart \& Werner Abraham (eds.), Studies in comparative Germanic syntax, 295-3II. Amsterdam: John Benjamins.

Merchant, Jason. 2006. Sluicing. In Martin Everaert \& Henk van Riemsdijk (eds.), The syntax companion, 269-289. London: Blackwell.

Pesetsky, David. 1987. Wh-in-situ: Movement and unselective binding. In Eric Reuland \& Alice G. B. ter Meulen (eds.), The representation of (in)definiteness, 98-I29. Cambridge, MA: MIT Press.

Postal, Paul M. 2005. Suppose (if only for an hour) that negative polarity items are negationcontaining phrases. Ms., New York University.

Postma, Gertjan. 1995. Zero semantics: A study of the syntactic conception of quantificational meaning. Ph.D. dissertation, University of Leiden.

Postma, Gertjan. 200I. Negative polarity and the syntax of taboo. In Hoeksema et al. (eds.), 283-330.

Pott, August F. I833. Etymologische Forschungen auf dem Gebiete der indo-germanischen Sprachen, vol. I. Lemgo: Meyer.

Potts, Christopher \& Thomas Roeper. 2006. The narrowing acquisition path: From expressive small clauses to declaratives. In Ljiljana Progovac, Kate Paesani, Eugenia Casielles \& Ellen Barton (eds.), The syntax of nonsententials: Multi-disciplinary perspectives, I83-20I. Amsterdam: John Benjamins.

Quirk, Randolph, Sidney Greenbaum, Geoffrey Leech \& Jan Svartvik. 1985. A comprehensive grammar of the English language. London \& New York: Longman.

Rollins, Bryant. 1967. Danger song. Garden City, NY: Doubleday.

Seuren, Peter A. M. I985. Discourse semantics. Oxford: Blackwell.

Simpson, John A. \& Edmund S. C. Weiner (eds.) 1989. The Oxford English dictionary, 2nd edn., vol. 4: Creel-duzepere. Oxford: Clarendon Press.

Slocum, Joshua. 1900. Sailing alone around the world. New York: The Century Co.

Sprouse, Jon. 2005. The accent projection principle: Why the hell not? In Aviad Eilam, Tatjana Scheffler \& Joshua Tauberer (eds.), Penn Working Papers in Linguistics I2.I, 349-359.

Szabolcsi, Anna. 2004. Positive polarity-negative polarity. Natural Language \& Linguistic Theory 22, 409-452.

van der Wouden, Ton. 1997. Negative contexts: Collocation, polarity, and multiple negation. London \& New York: Routledge.

Van Sterkenburg, Piet G. J. 200I. Vloeken: Een cultuurbepaalde reactie op woede, irritatie en frustratie, 2nd edn. The Hague: Sdu Uitgevers.

Walker, Daniel. 1968. Rights in conflict: The violent confrontation of demonstrators and police in the parks and streets of Chicago during the week of the Democratic National Convention of 1968. New York: Bantam Books.

Zwarts, Frans. 1995. Nonveridical contexts. Linguistic Analysis 25.3/4, 286-3I2. 


\section{J. HOEK SEMA \& D. J. NAPOLI}

Authors'addresses: (Hoeksema)

Department of Dutch Language and Culture,

Faculty of Letters, University of Groningen, P.O. Box 7I6, 9700 AS Groningen, The Netherlands.

j.hoeksema@rug.nl

(Napoli)

Department of Linguistics, Swarthmore College,

Swarthmore, PA I908I, U.S.A.

dnapoli!@swarthmore.edu 